\title{
Adsorption of crystal violet dye by agricultural rice bran waste: Isotherms, kinetics, modeling and influencing factors
}

\author{
Mojtaba Rezazadeh, Majid Baghdadi, Naser Mehrdadi, Mohammad Ali Abdoli ${ }^{\dagger}$ \\ Department of Environment Engineering, School of Engineering, University of Tehran, 4759184591, Tehran, Iran
}

\begin{abstract}
In this study, the potential of modified rice bran (MRB) was investigated for the elimination of crystal violet (CV) from plotted effluent. In this regard, rice bran (RB) was modified by chlorosulfonic acid. The results of FTIR, EDX, and SEM analysis showed structural change, an increase in the amount of sulfur, and the formation of a new band (998 and 1,225 cm $\mathrm{cm}^{-1}$ ) in MRB, respectively. The impact of different variables such as contact time, MRB dosage, $\mathrm{pH}, \mathrm{CV}$ concentration, and ions content on removal efficiency was studied by using batch experiments. In addition, response surface methodology was employed to optimize the experiments. The maximum removal efficiency of $97.4 \%$ was obtained at the adsorbent dosage of $2 \mathrm{~g} \mathrm{~L}^{-1}$, initial CV concentration of $100 \mathrm{mg} \mathrm{L}^{-1}$, and contact time of $42.75 \mathrm{~min}$. The highest adsorption capacity of $603 \mathrm{mg}^{-1}$ was acquired by the Langmuir model. The best description of kinetic data was achieved by the Elovich model. The thermodynamic study of the adsorption indicated an endothermic and spontaneous reaction. MRB could be regenerated by $\mathrm{HCl} 0.5 \mathrm{~mol} \mathrm{~L}^{-1}$ and removal efficiency was declined 10 percent after 5 adsorption/desorption cycles. It was concluded that MRB is an operational adsorbent to remove CV from effluents.
\end{abstract}

Keywords: Crystal violet, Kinetics, Low-cost adsorbent, Rice bran, Response Surface Methodology

\section{Introduction}

The emission of dyes by various industries into water bodies is a serious hazard for humans and the environment due to different chemical compounds and toxic materials [1, 2]. Globally, each year, 0.7 billion tons of paints are produced [3]. One of the popular pigments in the dyeing of cotton, silk, and wool is Crystal violet (CV). Aquaculture industries use this material as fungicide and antiseptic agents, and laboratories use it as an indicator because of its low cost and capabilities [4]. CV have cytogenetic effects on cells [5-7]. It can cause sore eyes, light sensitivity, digestive system irritability, and toxicity for mammals' cells [8, 9]. It has been reported that in high concentrations, it causes respiratory and kidney failure, cancer, and permanent blindness [10]. Moreover, another study also showed that CV even at low concentrations can cause induced cell death [11]. Considering extensive uses of crystal violet in industries despite its hazards, its removal from aqueous solutions is vital.

Different techniques have been evolved for the treatment of dyeing industries effluents in recent years, including adsorption [12], ultrafiltration [13], ozonation [14], precipitation [15], reverse osmosis [16], electrocoagulation [17], microbial degradation [18] and oxidative degradations [19]. Nevertheless, almost all mentioned techniques suffer from various disadvantages, such as inefficiency, temperature and $\mathrm{pH}$ sensitivity, secondary pollutions, high cost, and small scale application [20, 21]. Among these method, the adsorption method is known to be an efficient process for the treatment of dyed effluents due to its high efficiency, accessibility, flexibility, insensitivity to toxic materials, and its ease of work and administration compared to other conventional methods [22]. But, choosing adsorbent materials can escalate the cost. The by-products or wastes of agricultural activities such as banana peels [23], walnut wood [24], orange peels [25], sugarcane bagasse [26], rice husk [27], peanut hull [28, 29], Mango stone [30], Musa paradisiaca peels [31] and sweet potato peels [32] have been studied by researchers. However, adsorbents with high efficiency, availability, and low price are still needed.

Rice bran, which considered as food waste is a byproduct of the rice milling industry [33]. It mainly consists of cellulose, hemicellulose, lignin, and protein [34]. These materials, due to having molecules with active sites such as hydroxyl, carboxyl, and amino groups can easily attach to dyes [4]. They are also highly stable
This is an Open Access article distributed under the terms of the Creative Commons Attribution Non-Commercial License (http://creativecommons.org/licenses/by-nc/3.0/) which permits unrestricted non-commercial use, distribution, and reproduction in any medium, provided the original work is properly cited.

Copyright (C) 2021 Korean Society of Environmental Engineers
Received March 13, 2020 Accepted June 29, 2020

${ }^{\dagger}$ Corresponding author

Email: mabdoli@ut.ac.ir

Tel: +98 2161113171 Fax: +98 9111196525

ORCID: 0000-0002-0158-4891 
both chemically and physically [33]. Producing an adsorbent from cellulosic waste for treatment of dyes in effluent which have economic and environmental benefits, seems a proper replacement for conventional disposal methods.

The aim of the present study is to provide an effective adsorbent by chemical modification of rice bran, and finally its effectiveness in removing CV from polluted effluents was studied. Modified rice bran (MRB) and rice bran were characterized by Fourier transform infrared (FTIR), energy-dispersive X-ray spectroscopy (EDX), and scanning electron microscopy (SEM). To optimize the influential parameters (contact time, initial concentration, and adsorbent dosage) on the response of CV removal, response surface methodology (RSM) was used. Also, kinetics, equilibrium isotherms, different ions, and thermodynamics of adsorption were used to assess the results. Finally, the adsorbent regeneration was investigated.

\section{Material and Methods}

\subsection{Materials}

CV with a color index 42555, $\lambda_{\max }$ of $590 \mathrm{~nm}$, and chemical formula $\mathrm{C}_{25} \mathrm{H}_{30} \mathrm{~N}_{3} \mathrm{Cl}$ was purchased from Sigma-Aldrich. To prepare the stock solution of CV (1,000 mg L $\left.\mathrm{m}^{-1}\right), 250 \mathrm{ml}$ of distilled water was used to dissolve $273.8 \mathrm{mg}$ of CV. In all experiments, Deionized water was applied. Also, chlorosulfonic acid (CSA, $\mathrm{HSO}_{3} \mathrm{Cl}, 97 \%$ wt), dimethylformamide (DMF, $\mathrm{C}_{3} \mathrm{H}_{7} \mathrm{NO}, 99 \%$ wt), $\mathrm{HCl}$, and $\mathrm{NaOH}$ $\left(0.1 \mathrm{~mol} \mathrm{~L}^{-1}\right)$ were obtained from Merck. Also, the rice bran, which is a side product of the rice milling industry, was gathered from a grinding mill.

\subsection{Adsorbent Preparation}

In order to dry the rice bran, it was placed in an oven at $50^{\circ} \mathrm{C}$ for $24 \mathrm{~h}$. Then by sieving the dried barn, particles smaller than $425 \mu \mathrm{m}$ were separated. In a typical procedure, $8 \mathrm{~g}$ of the extracted bran was mixed with $100 \mathrm{ml}$ of DMF for $15 \mathrm{~min}$. $20 \mathrm{~g}$ of CSA has been steadily mixed with $100 \mathrm{ml}$ of DMF cautiously, then the mixed solution was placed in an ice bath. Subsequently, the resulting mixture was applied to RB and DMF gently and was shaken for $2 \mathrm{~h}$ at ambient temperature. The mixture was filtered using a $1 \mu \mathrm{m}$ membrane and neutralized by the proper amount of a sodium bicarbonate solution. The resulting mixture was washed several times by distilled water and filtered again. Finally, the mixture was dried at ambient temperature to obtain MRB. The corresponding process is shown in Fig. S1 (a), (b). The large volume of resulting DMF can be recycled at the end of reactions.

\subsection{Characterization of MRB}

For observation of active available functional groups of the adsorbent, the Fourier transform infrared (Bruker FTIR) analysis was used. Using scanning electron microscopy (SEM, model: HITACHI S-4160) the dimensions and morphology of the rice bran and MRB were studied. The composition of these materials was characterized by energy-dispersive X-ray spectroscopy (EDAX) and field emission scanning electron microscopy (FESEM, model: Mira 3-XMU).

\subsection{Batch Experiments Studies}

The removal of CV by MRB was carried out in a batch system. For this purpose, $50 \mathrm{~mL}$ of $\mathrm{CV}$ solution was mixed with an adequate amount of the adsorbent $(0.01-0.1 \mathrm{~g})$. Then it was agitated with a shaker at $150 \mathrm{rpm}$ at a fixed temperature. The initial $\mathrm{pH}(2-10)$ was adjasted using diluted $\mathrm{HCl}$ and $\mathrm{NaOH}$ solutions. Isotherms with various $\mathrm{CV}$ concentration $\left(100-1,000 \mathrm{mg} \mathrm{L}^{-1}\right)$ was studied while other parameters were kept constant. The kinetic study was carried out by altering the contact time from 2 to $60 \mathrm{~min}$. Additionally, the temperature varied between 279 and $328 \mathrm{~K}$ to analyze thermodynamic parameters.

Afterward, the residual CV was determined by a UV/VIS spectrophotometer (USA, DR 5000) at a peak wavelength of $590 \mathrm{~nm}$.

The removal percentage of CV by MRB was determined using the Eq. (1):

$$
\% \operatorname{Re} \text { moval }=\left(C_{0}-C_{e}\right) / C_{0} \times 100
$$

In this equation, Ce represents the final and Co shows the primary concentrations of CV [35].

\subsection{Experimental Design and Optimization}

The application of RSM is very common in the process of adsorption experiments planning for dye removal [9, 36]. The aim of using RSM is to concurrently optimize influential parameters in the adsorption process to find the best efficiency. The most important advantage of this methodology is reducing the number of experiments and preserving materials, energy, and time [37, 38]. RSM consists of statistical and mathematical techniques, which leads to a comprehensive analysis of the correlation between effective factors [25]. The Box-Behnken Design (BBD) is one of the significant designs of RSM. In this study, the BBD was used as a scheme in designing experiments for studying the correlation between the variables and predicting the most efficient conditions for the CV adsorption process, using the Design-Expert software (version, 10.0.4). Time (A: 2-60 min), initial concentrations of CV (C: 100-1,000 $\mathrm{mg} \mathrm{L}^{-1}$ ), and adsorbent dosage (B: 0.2-2 $\mathrm{g} \mathrm{L}^{-1}$ ) were selected as independent variables for the predicted response $(\mathrm{Y})$, and it was also considered as dependent outputs. According to BBD, a set of 17 runs was administered, involving five centered points with three parameters at three levels, and the results were presented in Table S1.

The correlation of the independent parameters and predicted response is explained using the quadratic equation (2):

$$
Y=b_{0}+\sum_{i=1}^{n} b_{i} x_{i}+\sum_{i=1}^{n} b_{i i} x_{i}{ }^{2}+\sum_{i \neq 1}^{n} b_{i j} x_{i} x_{j}
$$

Where $x_{i}$ and $x_{j}$ indicates are the independent variables as coded levels, $\mathrm{Y}$ is the response, $\mathrm{b}_{\mathrm{i} j}, \mathrm{~b}_{\mathrm{ii}}, \mathrm{b}_{\mathrm{i}}$, and $\mathrm{b}_{0}$ are the interaction, quadratic, linear, and intercept coefficients, respectively, and n is the number of independent variables [38]. The reliability of the fitted model and the statistical significance were evaluated by the correlation coefficient $\mathrm{R}^{2}$, analysis of variance (ANOVA), and P-value.

The compatibility of kinetic and equilibrium study with the experiment results was evaluated using the chi-square test $(\chi 2)$ 
and the residual root-mean-square error (RMSE). RMSE and $\chi^{2}$ must be minimum, and the best model is described by the minimum value for the error function [39].

\section{Results and Discussion}

\subsection{MRB Characterization}

The microstructure of rice bran and MRB was pictured using SEM analysis (Fig. 1 (a)-(d)). Raw rice bran contains organic matters such as starch, protein, and hemicellulose, which dissolves in acidic medium and move to the surface of rice bran. White spots in Fig. 1 (c) are white agglomerates, which are removed by chemical modification of rice bran [40]. These modifications are the result of sulfonation and hydrolysis in the acidic environment. In addition to these results, Fig. S2 (a), (b) shows the energy dispersive spectrum (EDX). The amount of sulfur in raw rice bran increased from 0.19 to $3.02 \%$, which indicates a successful chemical modification using chlorosulfonic acid.

Fig. 2 represents the FT-IR spectrum of rice bran and MRB. It is clear that the FT-IR spectrum of MRB shows an additional adsorption band at 998 and 1,225 $\mathrm{cm}^{-1}$. These new bands are related to the $\mathrm{S}-\mathrm{O}$ bond, which confirms that rice bran modification using chlorosulfonic acid was successful [41]. Adsorption band in the range of approximately $2,800-3,300 \mathrm{~cm}^{-1}$ can be assigned to hydroxyl groups, which is related to its organic matters such as hemicellulose, protein, and lignin. [42, 43]. The peak at 2,921 $\mathrm{cm}^{-1}$, which belongs to MRB, is almost vanished, demonstrating organic matters of raw rice bran were eliminated by CSA in the process of adsorbent synthesis.
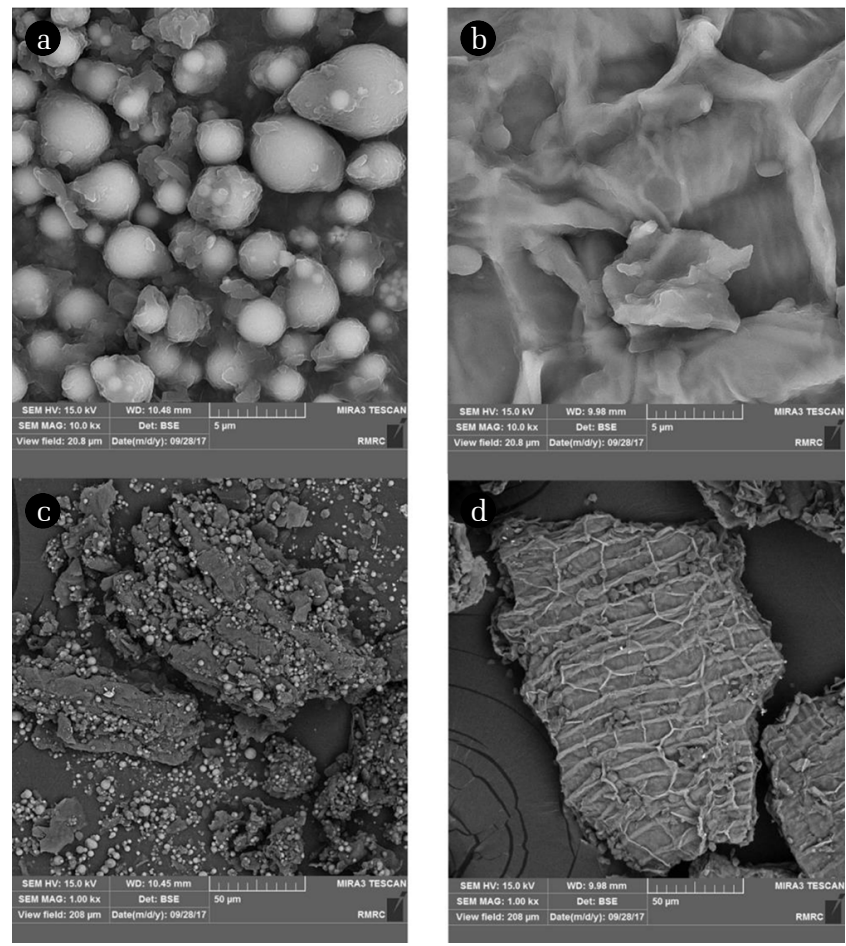

Fig. 1. The SEM pictures of rice bran. $((\mathrm{a}): \times 5 \mathrm{KX} ;(\mathrm{c}): \times 50 \mathrm{KX}$ and MRB (b): $\times 5 \mathrm{KX} ;(\mathrm{d}): \times 50 \mathrm{KX})$.

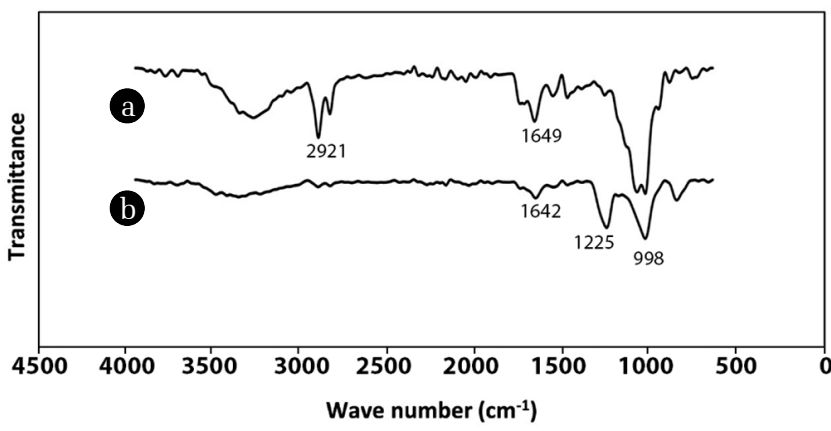

Fig. 2. The plots of FTIR (a) Rice bran, (b) MRB.

\subsection{Analysis of Variance (ANOVA)}

The following quadratic model BBD was obtained using the analysis of variance. This model describes the removal efficiency (Y) as a function of the concentration of CV (CV), adsorbent dosage (Ads), and contact time $(\mathrm{T})$.

$$
\begin{aligned}
\mathrm{Y}= & 45.9295+1.4073 \times \mathrm{T}+55.7759 \times \text { Ads }-0.09609 \times \\
& \mathrm{CV}+0.14065 \times \mathrm{T} \times \mathrm{Ads}+0.0004763 \times \mathrm{T} \times \mathrm{CV}+ \\
& 0.02209 \times \mathrm{Ads} \times \mathrm{CV}-0.0236 * \mathrm{~T}^{2}-15.6112 \times \mathrm{Ads}^{2}
\end{aligned}
$$

ANOVA results for the investigation of the model's validity and importance of variables are presented in Table 1. The large F-values and P-value of less than 0.05 show the significance of models and variables [43]. It is clear that linear terms of A (contact time), $\mathrm{B}$ (adsorbent dosage), and $\mathrm{C}$ (concentration of CV) and quadratic terms of $\mathrm{A}$ and $\mathrm{B}$ were considerable for $\mathrm{CV}$ removal using MRB. The interaction between variables (AC and $\mathrm{BC}$ ) was notable. Furthermore, the F-value of the model which is 492.88 along with low P-value $(\mathrm{p}<0.0001)$ indicates the high validity of the model. Compared to the pure error, the model's lack of fit was not considerable (0.3564). Consistency of the adjusted $\mathrm{R}^{2}$ and the anticipated $\mathrm{R}^{2}$ values supports the model's precision [44]. Fig. 3 (a) represents the normal probability of residuals for the removal efficiency of CV by MRB. It shows the symmetrical arrangement of experimental data within the level of confidence for the quadratic model [45].

Fig. 3 (b)-(d) show the surface plots of the model, which helps to understand interactions between parameters. The impact of contact time and adsorbent dosage on the percentage of CV removal is presented in Fig. 3 (b). By increasing contact time and adsorbent dosage, the CV removal increased. The strong relation between adsorbent dosage and initial concentration of CV is seen in Fig. 3 (c). This relation can be deduced from low high F-value and $\mathrm{P}$-value [45]. Increasing the adsorbent dosage increases the CV removal, this is a result of the increasing number of adsorbent active removing more dye from the aqueous solution [46]. Fig. 3 (d) shows the impact of contact time and initial concentration of pollutants. At low CV concentration, the adsorption process is faster because in this condition adsorbent active sites are more accessible to adsorbate molecules of dye [47]. Finally, the maximum removal efficiency of $97.4 \%$ was calculated by the model analysis at initial CV concentration of $100 \mathrm{mg} \mathrm{L}^{-1}$, contact time of 42.75 min, and adsorbent dosage of $2 \mathrm{~g} \mathrm{~L}^{-1}$. 
Table 1. ANOVA Result for CV Removal by MRB

\begin{tabular}{|c|c|c|c|c|c|}
\hline Term & Mean Square & Degree of Freedom & Sum of Square & F-value & p-value \\
\hline Model & 1927.27 & 8 & 15418.15 & 161.23 & $<0.0001$ \\
\hline A- contact time & 869.43 & 1 & 869.43 & 72.73 & $<0.0001$ \\
\hline B- Adsorbent & 6683.5 & 1 & 6683.5 & 559.12 & $<0.0001$ \\
\hline C- CV & 3773.16 & 1 & 3773.16 & 315.65 & $<0.0001$ \\
\hline $\mathrm{AB}$ & 53.9 & 1 & 53.9 & 4.51 & 0.0714 \\
\hline $\mathrm{AC}$ & 154.54 & 1 & 154.54 & 12.93 & 0.0088 \\
\hline $\mathrm{BC}$ & 178.76 & 1 & 178.76 & 14.95 & 0.0062 \\
\hline$A^{2}$ & 1403.15 & 1 & 1403.15 & 117.38 & $<0.0001$ \\
\hline $\mathrm{B}^{2}$ & 548.22 & 1 & 548.22 & 45.86 & 0.0003 \\
\hline Residual & 11.95 & 7 & 83.67 & & \\
\hline Lack of Fit & 14.47 & 3 & 43.42 & 1.44 & 0.3564 \\
\hline Pure Error & 10.06 & 4 & 40.25 & & \\
\hline Cor. Total & & 15 & 15501.82 & & \\
\hline
\end{tabular}

Pred $\mathrm{R}^{2}=0.9599, \mathrm{R}^{2}=0.9946$, Adj. $\mathrm{R}^{2}=0.9884$
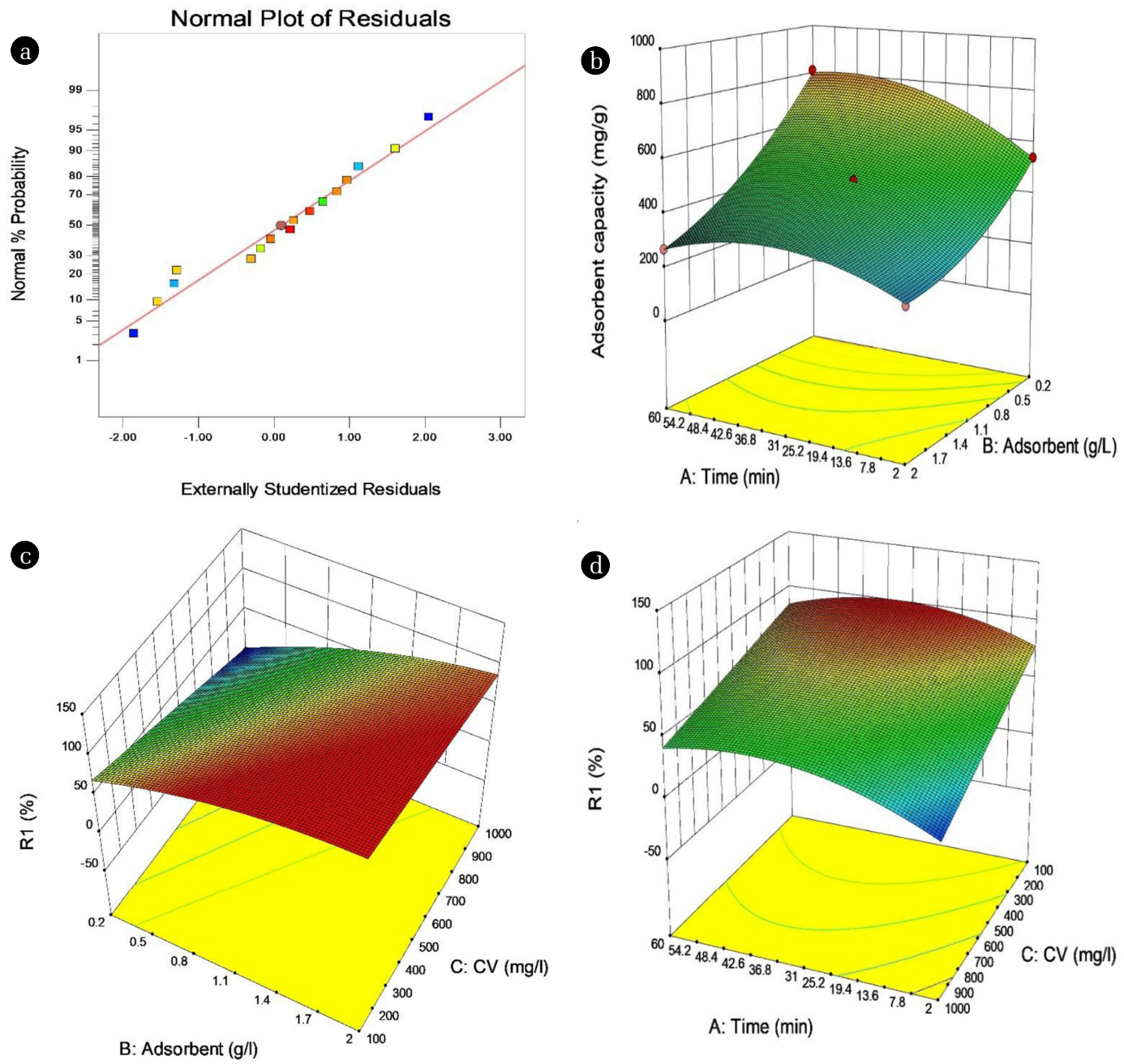

Fig. 3. (a) Plot of normal probability for CV removal using MRB. 3D surface: (b) Time-MRB (c) MRB dosage-CV concentration (d) Time-CV concentration. 


\section{3. pH Effect on The Removal Efficiency}

One of the most crucial parameters in dye removal is $\mathrm{pH}$ because it can affect the density of the adsorbent surface charge, thereby affecting the dye removal efficiency [43]. $\mathrm{pH}$ was investigated in range of 2 to 10 to study its impact on the CV removal by MRB. Fig. 4 (a) shows the results. Moreover, the point of zero charge for MRB was found at around 2. There is not a competition between $\mathrm{H}^{+}$ions and CV to occupy the active sites of MRB because sulfate group of MRB keeps its charge even in acidic medium. As a consequence, the removal efficiency was constan in $\mathrm{pH}$ range of 2-7. The $\mathrm{pH}_{\mathrm{PZC}}$ value confirmed these explanations. When $\mathrm{pH}$ goes up from 7 to 10, the removal efficiency increased because of precipitation of $\mathrm{CV}$ at the high concentration of $\mathrm{OH}^{-}$.

\subsection{Ions Effect}

Impact of $\mathrm{K}^{+}, \mathrm{NO}_{3}{ }^{-}, \mathrm{Na}^{+}, \mathrm{SO}_{4}{ }^{2-}, \mathrm{Ca}^{2+}, \mathrm{Mg}^{2+}, \mathrm{HCO}_{3}{ }^{-}$and $\mathrm{Cl}^{-}$on $\mathrm{CV}$ removal by MRB was studied (Fig. 4 (b)).To compare the impact of different ions on the CV removal process, eight samples and a control sample were used. The control sample marked as A in the chart. $\mathrm{Ca}^{2+}$ and $\mathrm{Mg}^{2+}$ ions compete with $\mathrm{CV}$ for active adsorption sites because of their positive charges; therefore, thereby decreasing the removal efficiency. $\mathrm{Na}^{+}$and $\mathrm{K}^{+}$also present positive charge as Calcium and Magnesium. In Fig. 4, we can observe a small reduction in dy removal in the presence of $\mathrm{Na}^{+}$and $\mathrm{K}^{+}$ions. However, for $\mathrm{Ca}^{2+}$ and $\mathrm{Mg}^{2+}$, this reduction was more evident, because these ions are divalent, while $\mathrm{Na}^{+}$and $\mathrm{K}^{+}$are monovalent, showing low ineraction with positive active sites. The other ions did not affect the dye removal.
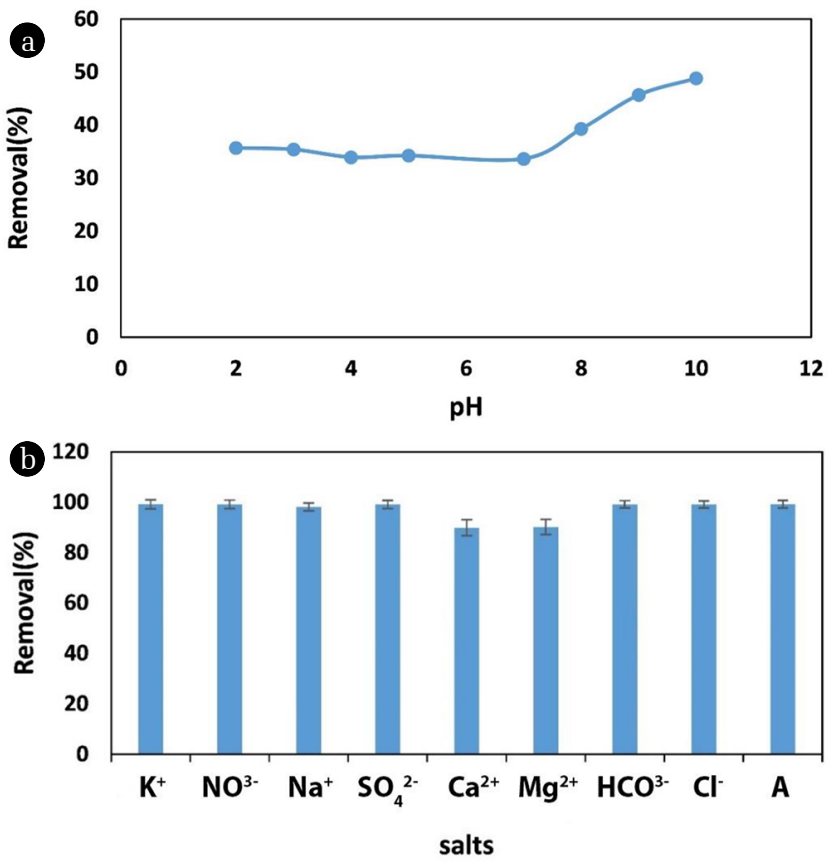

Fig. 4. (a) $\mathrm{pH}$ Effect on the $\mathrm{CV}$ removal using MRB: MRB: $600 \mathrm{mg}$ $\mathrm{L}^{-1}$, Temperature: $298 \mathrm{~K}, \mathrm{CV}: 1,000 \mathrm{mg} \mathrm{L}^{-1}$, Time: $60 \mathrm{~min}$. (b) Impact of different ions on CV removal: MRB: $600 \mathrm{mg} \mathrm{L}^{-1}$, Temperature: $298 \mathrm{~K}, \mathrm{CV}: 200 \mathrm{mg} \mathrm{L}^{-1}$, Time: $60 \mathrm{~min}$.

\subsection{Equilibrium Studies}

Different isotherm equations including Radke-Prausnitz, Freundlich, UT, Temkin, Langmuir, Redlich-Peterson, and, Dubinin-Radushkevich models were used to investigate the isotherms data in the equilibrium state [48-50]. Also, the linear form of these models was used and the results are represented in Table 2 for the adsorption of CV by MRB. Different error functions, represented in Table S2, are used to investigate the performance of these models. Redlich-Peterson, UT, and Radke-Prausnitz isotherms have the lowest errors, while maximum error belongs to Dubinin-Radushkevich model, which could not fit the data well. The fitting degree followed the sequence:

Radke-Prausnitz $=$ UT $=$ Redlich-Peterson $>$ Langmuir $>$ Temkin $>$ Freundlich $>$ Dubinin-Radushkevich.

The adsorption isotherms and experimental data are indicated in Fig. 5 (a). Also Residual graph for different isotherms are shown in Fig. 5 (b) which confirm the results of error analysis. Value of non-dimensional factor $\left(\mathrm{R}_{\mathrm{L}}\right)$ in the Langmuir model, for different initial concentration of $\mathrm{CV}$, was calculated in the range of 0.11 to 0.5 , suggesting a favorable process for adsorption of CV by MRB. It is known that a nearly zero value for $1 / \mathrm{n}_{\mathrm{f}}$ calculated by the Freundlich model suggests a more heterogeneous surface for the adsorbent [49]. In this experiment, the calculated value was 0.473 , which was consistent with this concept. The calculated values for maximum capacity corresponding to Dubinin-Radushkevich, Radke-Prausnitz, UT, and Langmuir isotherms were 404, 600, 603, and $600 \mathrm{mg} \mathrm{g}^{-1}$, respectively. It should be noted that the calculated values of UT and Radke-Prausnits were equal and very close to the Langmuir model result. The values of the Dubinin-Radushkevich model was far below the experimental results.
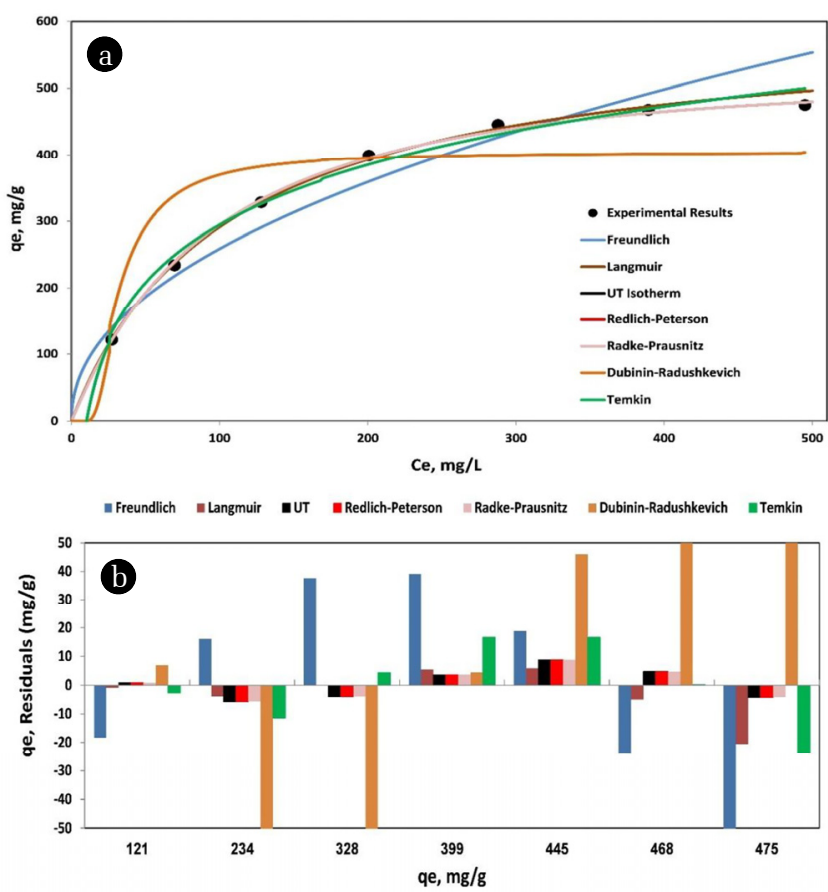

Fig. 5. The isotherms of $C V$ removal using MRB (a), Residual graph for different models (b). MRB: $600 \mathrm{mg} \mathrm{L}^{-1}$, Temperature: $298 \mathrm{~K}$, Time: $60 \mathrm{~min}$. 
Table 2. Parameters of Isotherm for CV Removal Using MRB

\begin{tabular}{|c|c|c|c|c|}
\hline Model & Equation & & Parameters & value \\
\hline Dubinin-Radushkevich & $E=\frac{1}{\sqrt{2 \beta}}$ & (4) & $E: \mathrm{kJ} \mathrm{mol}{ }^{-1}$ & 18.87 \\
\hline \multirow{5}{*}{ UT Isotherm } & $\varepsilon=R T \ln \left(1+\frac{1}{C_{e}}\right)$ & (5) & $\beta: \mathrm{mol}^{2} \mathrm{~J}^{-2}$ & $1.4 \times 10^{-3}$ \\
\hline & $\ln q_{e}=\ln q_{s}-\beta \varepsilon^{2}$ & (6) & $q_{s}: \mathrm{mg} \mathrm{g}^{-1}$ & 404 \\
\hline & $\ln \left(\frac{C_{e}}{C_{e}^{a d}}-\frac{K_{d}}{C_{m}}\right)=-b \ln C_{m}+b \ln C_{e}$ & (7) & $F C F$ & 0.314 \\
\hline & & & $b$ & 1.076 \\
\hline & & & $K_{d}: \mathrm{mg} \mathrm{L}^{-1}$ & 113 \\
\hline \multirow{4}{*}{ Langmuir } & & \multirow{4}{*}{ (8) } & $q_{m}=\frac{C_{m}}{D}: \mathrm{mg} \mathrm{L}^{-1}$ & 600 \\
\hline & $\underline{C_{e}}=\frac{1}{C_{e}}$ & & $K_{L}: \mathrm{L} \mathrm{mg}^{-1}$ & 0.0093 \\
\hline & $\overline{q_{e}}=\overline{K_{L} q_{m}}+\overline{q_{m}}$ & & $q_{m}: \mathrm{mg} \mathrm{L}^{-1}$ & 603 \\
\hline & $R_{L}=\frac{1}{1+K_{L} \times C_{0}}$ & & $\mathrm{R}_{\mathrm{L}}$ & $0.11-0.5$ \\
\hline \multirow[t]{3}{*}{ Radke-Prausnitz } & $\frac{C_{e}}{e_{e}}=\frac{1}{K}+\frac{C_{e}^{m}}{K_{e}}$ & (9) & $K_{R P}: \mathrm{L}$ mg-1 & $5.62 \times 10-3$ \\
\hline & & & $q_{m}: \mathrm{mg} \mathrm{g}^{-1}$ & 600 \\
\hline & & & $m$ & 1.076 \\
\hline \multirow[t]{3}{*}{ Redlich-Peterson } & $\ln \left(K_{R} \frac{C_{e}}{q_{e}}-\right)=g \ln C_{e}+\ln \alpha_{R}$ & (10) & $\alpha_{R}:\left(\mathrm{L} \mathrm{mg}^{-1}\right) \mathrm{g}$ & $5.62 \times 10-3$ \\
\hline & & & $K_{R}: \mathrm{L} \mathrm{g}^{-1}$ & 5.3 \\
\hline & & & $g$ & 1.076 \\
\hline \multirow[t]{2}{*}{ Temkin } & $q_{e}=B_{1} \ln A+B_{1} \ln C_{e}$ & (11) & $B_{1}: \mathrm{mg} \mathrm{g}^{-1}$ & 129.1 \\
\hline & & & $A: \mathrm{L} \mathrm{mg-}^{1}$ & 0.096 \\
\hline \multirow[t]{2}{*}{ Freundlich } & $\ln q_{e}=\ln K_{F}+\frac{1}{n_{F}} \ln C_{e}$ & $(12)$ & $K_{F}:\left(\mathrm{mg} \mathrm{g}^{-1}\right)\left(\mathrm{L} \mathrm{mg}^{-1}\right)^{1 / \mathrm{n}}$ & 29.31 \\
\hline & & & $1 / \mathrm{nF}$ & 0.473 \\
\hline
\end{tabular}

$E$ : average energy of adsorption, $\beta$ : Dubinin-Radushkevich constant, $q_{s}$ : adsorption capacity, $q_{m}:$ maximum capacity of adsorption, $K_{R P}$ : constant of Radke-Prausnitz, $F C F$ : UT dimensionless factor, $b$ : UT exponent, $K d$ : desorption constant, $K_{F}:$ Freunlich constant shows the adsorption capacity, $1 / n$ : Freunlich constant shows the adsorption intensity, $\alpha R$ and $K_{R}:$ and $g:$ constants of Redlich-Peterson, $R$ : gas constant 8.314, $K_{L}$ : Langmuir constant, $B 1$ and $A$ : constant of Temkin

\subsection{Kinetic Studies}

For determining and explaining the adsorption rate, it is vital to analyze kinetics data [43]. Various kinetics are used to examine the removal of CV by MRB at two different concentrations (500 and $750 \mathrm{mg} \mathrm{L}^{-1}$ ). Residual root-mean-square error (RMSE), the result of kinetic parameters, the linear form of these kinetics, chi-square test $\left(\chi^{2}\right)$, and the coefficients of determination $\left(\mathrm{R}^{2}\right)$ are shown in Table 3 [27, 51]. According to $\chi^{2}, \mathrm{R}^{2}$, and RMSE, liquid film diffusion and pseudo-first-order models were not sucessful in fitting experimental data, while the Elovich model showed a good fit for it. Also, it should be noted that the intra-particle diffusion model was better than the pseudo-second-order model. The experimental 
Table 3. Parameters of Kinetic for CV Removal Using MRB

\begin{tabular}{|c|c|c|c|c|c|c|c|}
\hline \multirow{2}{*}{ Model } & & \multirow{2}{*}{ Parameters } & \multicolumn{2}{|c|}{ Concentration $\left(\mathrm{mgL}^{-1}\right)$} & \multirow{2}{*}{$\begin{array}{c}\text { Error } \\
\text { Function }\end{array}$} & \multicolumn{2}{|c|}{ Concentration $\left(\mathrm{mgL}^{-1}\right)$} \\
\hline & & & 500 & 750 & & 500 & 750 \\
\hline Elovich & & $\alpha: \mathrm{g} \mathrm{mg}^{-1}$ & 541.33 & 181.22 & $\chi^{2}$ & 171 & 158 \\
\hline \multirow{2}{*}{$q_{t}=\frac{1}{\beta} \ln (\alpha \beta)+\frac{1}{\beta} \ln (t)$} & (13) & $\beta: \mathrm{mg} \mathrm{g}^{-1} \min ^{-1}$ & 0.0115 & $6.89 \mathrm{E}-3$ & RMSE & 139 & 138 \\
\hline & & & & & $\mathrm{R}^{2}$ & 0.993 & 0.991 \\
\hline Liquid film diffusion & & $k_{f d}: \min ^{-1}$ & 0.1179 & 0.1009 & $\chi^{2}$ & 371 & 305 \\
\hline \multirow[t]{2}{*}{$\ln (1-F)=-k_{f d} t$} & (14) & & & & RMSE & 146 & 142 \\
\hline & & & & & $\mathrm{R}^{2}$ & 0.982 & 0.98 \\
\hline Pseudo-second-order & & $q_{e}$ (calc.): $\mathrm{mg} \mathrm{g}^{-1}$ & 636 & 835 & $\chi^{2}$ & 232 & 200 \\
\hline \multirow[t]{2}{*}{$\frac{t}{q_{t}}=\frac{1}{k_{2} q_{e}^{2}}+\left(\frac{1}{q_{e}}\right) t$} & (15) & $\mathrm{k}_{2}: \mathrm{g} \mathrm{mg}^{-1} \min ^{-1}$ & $2.18 \mathrm{E}-4$ & $9.69 \mathrm{E}-5$ & RMSE & 125 & 123 \\
\hline & & & & & $\mathrm{R}^{2}$ & 0.997 & 0.993 \\
\hline Intraparticle diffusion & & $C:$ & 202.55 & 105.04 & $\chi^{2}$ & 316 & 273 \\
\hline \multirow[t]{2}{*}{$q_{t}=k_{d i f} t^{1 / 2}+C$} & (16) & $k_{\text {dif }}: \mathrm{mg} \mathrm{g}^{-1} \min ^{-1 / 2}$ & 47.99 & 80.41 & RMSE & 150 & 148 \\
\hline & & & & & $\mathrm{R}^{2}$ & 0.998 & 0.999 \\
\hline Pseudo-first-order & & $q_{e}$ (calc.): $\mathrm{mg} \mathrm{g}^{-1}$ & 320 & 482 & $\chi^{2}$ & 828 & 388 \\
\hline \multirow[t]{2}{*}{$\log \left(q_{e}-q_{t}\right)=\log \left(q_{e}\right)-\frac{k_{1} t}{2.303}$} & (17) & $k_{1}: \min ^{-1}$ & 0.1087 & 0.0927 & RMSE & 195 & 163 \\
\hline & & & & & $\mathrm{R}^{2}$ & 0.982 & 0.98 \\
\hline
\end{tabular}

$k_{f d}$ : coefficients of diffusion rate for liquid film, $c$ : intercept of intraparticle diffusion, $\beta$ : and $\alpha$ : desorption constant and primary velocity rate of Elovich, $q_{e}$ : the capacity of equilibrium, $k_{1}:$ pseudo-first-order constant Rate, $k_{2}:$ constant of second-order rate, $k_{d i f}$ : intraparticle diffusion constant.

data and predicted data using kinetic models are indicated in Fig. S3. It is clear that Elovich and intra-particle diffusion models were well described all data.

At $298 \mathrm{~K}$, by increasing concentration of dye (500 to $750 \mathrm{mg}$ $\left.\mathrm{L}^{-1}\right)$, the $\mathrm{k}_{2}\left(2.18 \times 10^{-4}\right.$ to $\left.9.69 \times 10^{-5} \mathrm{~g} \mathrm{mg}^{-1} \mathrm{~min}^{-1}\right)$ decreased, so it can be concluded that adsorption is slower at lower concentration of $\mathrm{CV}$.

The Fig. S1 (c) shows a schematic of the CV which is positively charged, attached to the negatively charged functional groups of adsorbent. Also, to identify the mechanism of adsorption, kinetics data were investigated by adsorption diffusion model. This model is based on three consecutive steps. The first step is diffusion across the liquid film surrounding the adsorbent particles (external diffusion or film diffusion). The second step is diffusion within the pores of adsorbent (internal diffusion or intra-particle diffusion). Finally the third step is adsorption of adsorbate by internal active sites [8]. The plot of $\ln \left(1-\left(\mathrm{q}_{\mathrm{t}} / \mathrm{q}_{\mathrm{e}}\right)\right)$ versus $t$ should be a straight line if the film diffusion is the rate determining step. Also, the plot of $q_{t}$ against $t^{1 / 2}$ passing through the origin if the intraparticle diffusion act as the only rate-limiting step [47]. Otherwise, the adsorption kinetics may be controlled by film diffusion and intraparticle diffusion simultaneously. It was seen that in our experiment, the plotted line dose not pass through the origin, so both intraparticle diffusion and film diffusion are the rate-controlling step. Furthermore, the constant of intraparticle diffusion $\left(\mathrm{k}_{\mathrm{dif}}\right)$ increased by increasing dye concentration, as an outcome of the rise in the driving force.

Initial adsorption rate $(\alpha)$ and the desorption constant ( $\beta$ ) appear in the Elovich equation (Eq. (13)). High $\beta$ value indicates a lower driving force [27]. According to Table 3, when CV concentration increases the Elovich constant $(\beta)$ decreases, and as a result, the adsorption constant $(\alpha)$ increases. This decrease in $\beta$ is an indication of increasing the driving force (between $\mathrm{CV}$ and MRB molecules), and as a result better adsorption occurs.

\subsection{Thermodynamic Study}

To determine values of standard entropy $\Delta \mathrm{S}\left(\mathrm{J} \mathrm{mol}^{-1} \mathrm{~K}^{-1}\right)$, standard free energy $\Delta \mathrm{G}\left(\mathrm{J} \mathrm{mol}^{-1}\right)$ and standard enthalpy $\Delta \mathrm{H}\left(\mathrm{J} \mathrm{mol}^{-1}\right)$, the thermodynamic analysis was directed in CV removal by MRB at various temperature (279-328k) using following equations:

$$
\begin{gathered}
K_{e}=\frac{q_{e}}{C_{e}} \\
\Delta G=-R T \ln \left(K_{e}\right)
\end{gathered}
$$




$$
\ln \left(K_{e}\right)=\frac{-\Delta H}{R T}+\frac{\Delta S}{R}
$$

Where Ke is the distribution coefficient, $\mathrm{T}$ is the temperature $(\mathrm{K})$, and $\mathrm{R}$ is the constant of thermodynamic gas $\left(8.314 \mathrm{~J} \mathrm{~mol}^{-1}\right.$ $\left.\mathrm{K}^{-1}\right)$. The thermodynamic constants $(\Delta \mathrm{G}, \Delta \mathrm{S}$, and $\Delta \mathrm{H})$ are given in Table S3 [51]. The adsorption of CV by MRB is an endothermic physisorption because the enthalpy $(\Delta \mathrm{H})$ value was positive and less than $40 \mathrm{Jmol}^{-1} \mathrm{~K}^{-1}$ [35]. The $\Delta S$ of adsorption had positive value since the randomness increased in the solid/solution interface. A negative amount of $\Delta \mathrm{G}$ displays $\mathrm{CV}$ removal using MRB is a spontaneous reaction.

\subsection{Desorption Study}

The adsorbent becomes more efficient if it can be reused. In that case, it would bring more economic and environmental benefits (46). To achieve this purpose, MRB was regenerated with a $\mathrm{HCl}$ solution $\left(0.5 \mathrm{~mol} \mathrm{~L}^{-1}\right)$. After the adsorption process, MRB was separated from the $\mathrm{CV}$ solution, then it was mixed with $\mathrm{HCl}$ (0.5 mol $\mathrm{L}^{-1}$ ) and shaken for $30 \mathrm{~min}$. Subsequently, the resulting mixture was washed with deionized water. As Fig. S4 shows, five cycles of adsorption/desorption reduce the dye removal efficiency by $10 \%$, which shows the excellent ability of regenerated MRB in CV removal.

\subsection{Comparision of The Capacities of MRB with Other Materials for The CV Removal}

Several adsorbents for the CV removal were used, which their maximum adsorption capacities are presented in Table S4. The adsorption capacity of MRB was much more than other agricultural waste materials; it can be concluded that modification of rice bran increased its adsorption capacity.

\section{Conclusions}

In this research, a simple technique was suggested for modification of rice bran, as advantageous utilization of agricultural waste, to remove CV from aqueous solutions. Rice bran was successfully modified. The removal efficiency was independent of $\mathrm{pH}$ in the range of 2-7. For optimization and modeling of the adsorption process, BBD of the RSM was used. ANOVA analysis indicated that utilized models in this study were appropriate. Increasing adsorbent dosage and contact time increased the CV removal. Different ions did not have an adverse influence on the dye removal owing to the strong tendency between the modified group of MRB and CV. Equilibrium and kinetic adsorption data were well fitted by Redlich-Peterson, UT and Radke-Prausnitz isotherms and Elovich models, respectively. Kinetic models were studied at different concentrations. By increasing dye concentration, the Elovich constant $(\beta)$ and pseudo-second-order rate constant $\left(\mathrm{k}_{2}\right)$ decreased. The most important properties of MRB include high adsorption capacity (603 $\mathrm{mg} \mathrm{g}^{-1}$ ) as well as the low cost and recoverability. The results of this study show that MRB has a high ability to eliminate CV from polluted effluents. Producing the adsorbent from MRB seems a proper replacement for conventional disposal methods.

\section{Author Contributions}

M.R. (Ph.D. student) conducted all experiments and data analyses and prepared the manuscript. M.B. (Ph.D., Associate professor) overseeing experiments and data analyses and revised the manuscript. N. M. (Ph.D., Professor) overseeing experiments and data analyses and revised the manuscript. M.A.A. (Ph.D., Professor) overseeing experiments and data analyses and revised the manuscript.

\section{References}

1. Shindy A. Problems and solutions in colors, dyes and pigments chemistry: a review. Chem. Int. 2017;3:97-105.

2. Sohrabi MR, Moghri M, Fard Masoumi HR, Amiri S, Moosavi N. Optimization of Reactive Blue 21 removal by Nanoscale Zero-Valent Iron using response surface methodology. Arab. J. Chem. 2016;9:518-525.

3. Bhatti HN, Jabeen A, Iqbal M, Noreen S, Naseem Z. Adsorptive behavior of rice bran-based composites for malachite green dye: Isotherm, kinetic and thermodynamic studies. J. Mol. Liq. 2017;237:322-333.

4. Georgin J, Marques BS, Peres EC, Allasia D, Dotto GL. Biosorption of cationic dyes by Pará chestnut husk (Bertholletia excelsa). Water Sci. Technol. 2018;77:1612-1621.

5. Iqbal M, Abbas M, Nisar J, Nazir A. Bioassays based on higher plants as excellent dosimeters for ecotoxicity monitoring: A review. Chem. Int. 2019;5:1-80.

6. Tahir MA, Bhatti HN, Hussain I, Bhatti IA, Asghar M. Sol-Gel Synthesis of Mesoporous Silica-Iron Composite: Kinetics, Equilibrium and Thermodynamics Studies for the Adsorption of Turquoise-Blue X-GB Dye. Zeitschrift Fur. Phys. Chemie. 2020;234:233-253.

7. Kamran U, Bhatti HN, Iqbal M, Jamil S, Zahid M. Biogenic synthesis, characterization and investigation of photocatalytic and antimicrobial activity of manganese nanoparticles synthesized from Cinnamomum verum bark extract. J. Mol. Struct. 2019;1179:532-539.

8. Mittal A, Mittal J, Malviya A, Kaur D, Gupta VK. Adsorption of hazardous dye crystal violet from wastewater by waste materials. J. Colloid. Interface. Sci. 2010;343:463-743.

9. Ruan W, Hu J, Qi J, Hou Y, Cao R, Wei X. Removal of crystal violet by using reduced-graphene-oxide-supported bimetallic $\mathrm{Fe} / \mathrm{Ni}$ nanoparticles (rGO/Fe/Ni): Application of artificial intelligence modeling for the optimization process. Materials (Basel) 2018;11:1-27.

10. Chakraborty S, Chowdhury S, Das Saha P. Adsorption of Crystal Violet from aqueous solution onto $\mathrm{NaOH}$-modified rice husk. Carbohydr Polym. 2011;86:1533-1541.

11. Ventura-Camargo B de C, Parise Maltempi PP, Aparecida M, Morales M. The use of the Cytogenetic to Identify Mechanisms of Action of an Azo Dye in Allium Cepa Meristematic Cells. J. Environ. Anal. Toxicol. 2011;01:1-12.

12. Fazal-ur-Rehman M. Methodological trends in preparation of activated carbon from local sources and their impacts on production: A review. Chem. Int. 2018;4:109-119. 
13. Awwad AM, Amer MW, Al-aqarbeh MM. TiO 2 -kaolinite nanocomposite prepared from the Jordanian Kaolin clay: Adsorption and thermodynamics of $\mathrm{Pb}$ (II) and $\mathrm{Cd}$ (II) ions in aqueous solution. Chem. Int. 2020;6:168-178.

14. Konsowa AH. Decolorization of wastewater containing direct dye by ozonation in a batch bubble column reactor. Desalination 2003;158:233-240.

15. Minas F, Chandravanshi BS, Leta S. Chemical precipitation method for chromium removal and its recovery from tannery wastewater in Ethiopia. Chem. Int. 2017;3:392-405.

16. Oussama N, Bouabdesselam H, Ghaffour N, Abdelkader L. Characterization of seawater reverse osmosis fouled membranes from large scale. Chem. Int. 2019;5:158-167.

17. Daij KB, Bellebia S, Bengharez Z. Comparative Experimental Study On The Cod Removal In Aqueous Solution Of Pesticides By The Electrocoagulation Process Using Monopolar Iron Electrodes. Chem. Int. 2017;3:319-327.

18. Ukpaka C. BTX degradation: the concept of microbial integration. Chem. Int. 2016;3:8-18.

19. Iqbal M, Ahmad MZ, Bhatti IA, Qureshi K, Khan A. Cytotoxicity reduction of wastewater treated by advanced oxidation process. Chem. Int. 2015;1:53-59.

20. Ahmad A, Mohd-Setapar SH, Chuong CS, et al. Recent advances in new generation dye removal technologies: Novel search for approaches to reprocess wastewater. RSC Adv. 2015;5:30801-30818.

21. Ezechi EH, Kutty SRBM, Malakahmad A, Isa MH. Characterization and optimization of effluent dye removal using a new low cost adsorbent: Equilibrium, kinetics and thermodynamic study. Process Saf. Environ. Prot. 2015;98:16-32.

22. Singh H, Chauhan G, Jain AK, Sharma SK. Adsorptive potential of agricultural wastes for removal of dyes from aqueous solutions. J. Environ. Chem. Eng. 2017;5:122-135.

23. Munagapati VS, Yarramuthi V, Kim Y, Lee KM, Kim D-S. Removal of anionic dyes (Reactive Black 5 and Congo Red) from aqueous solutions using Banana Peel Powder as an adsorbent. Ecotoxicol. Environ. Saf. 2018;148:601-607.

24. Hajati S, Ghaedi M, Mazaheri H. Removal of methylene blue from aqueous solution by walnut carbon: optimization using response surface methodology. Desalin. Water Treat. 2016;57:3179-3193.

25. Oyekanmi AA, Ahmad A, Hossain K, Rafatullah M. Statistical optimization for adsorption of Rhodamine B dye from aqueous solutions. J. Mol. Liq. 2019;281:48-58.

26. Noreen S, Bhatti HN, Iqbal M, Hussain F, Sarim FM. Chitosan, starch, polyaniline and polypyrrole biocomposite with sugarcane bagasse for the efficient removal of Acid Black dye. Int. J. Biol. Macromol. 2020;147:439-452.

27. Bhatti HN, Safa Y, Yakout SM, Shair OH, Iqbal M, Nazir A. Efficient removal of dyes using carboxymethyl cellulose/alginate/polyvinyl alcohol/rice husk composite: Adsorption/desorption, kinetics and recycling studies. Int. J. Biol. Macromol. 2020;150:861-870.

28. Tahir N, Bhatti HN, Iqbal M, Noreen S. Biopolymers composites with peanut hull waste biomass and application for Crystal Violet adsorption. Int. J. Biol. Macromol. 2017;94:210-220.

29. Yang J, Ji G, Gao Y, et al. High-yield and high-performance porous biochar produced from pyrolysis of peanut shell with low-dose ammonium polyphosphate for chloramphenicol adsorption. J. Clean Prod. 2020;264:121516.

30. Shoukat S, Bhatti HN, Iqbal M, Noreen S. Mango stone biocomposite preparation and application for crystal violet adsorption: A mechanistic study. Microporous. Mesoporous. Mater. 2017;239:180-9.

31. Ibisi N, Asoluka C. Use of agro-waste (Musa paradisiaca peels) as a sustainable biosorbent for toxic metal ions removal from contaminated water. Chem. Int. 2018;4:52-59.

32. Chidi O, Kelvin R. Surface interaction of sweet potato peels (Ipomoea batata) with $\mathrm{Cd}$ (II) and $\mathrm{Pb}$ (II) ions in aqueous medium. Chem. Int. 2018;4:221-229.

33. Jia M, Chen J, Liu X, et al. Structural characteristics and functional properties of soluble dietary fiber from defatted rice bran obtained through Trichoderma viride fermentation. Food Hydrocoll. 2019;94:468-474.

34. Zhang W, Yan H, Li H, et al. Removal of dyes from aqueous solutions by straw based adsorbents: Batch and column studies. Chem. Eng. J. 2011;168:1120-1127.

35. Wei J, Xu J, Mei Y, Tan Q. Chloride adsorption on aminobenzoate intercalated layered double hydroxides: Kinetic, thermodynamic and equilibrium studies. Appl. Clay Sci. 2020;187:105495.

36. Moradi N, Salem S, Salem A. Optimizing adsorption of blue pigment from wastewater by nano-porous modified Na-bentonite using spectrophotometry based on response surface method Spectrochim Acta - Part A Mol. Biomol. Spectrosc. 2018;193:54-62.

37. Li B, Gan L, Owens G, Chen Z. New nano-biomaterials for the removal of malachite green from aqueous solution via a response surface methodology. Water Res. 2018;146:55-66.

38. Ghosh RK, Ray DP, Debnath S, Tewari A, Das I. Optimization of process parameters for methylene blue removal by jute stick using response surface methodology. Environ. Prog. Sust. Energy. 2019;38:13146.

39. Behjati M, Baghdadi M, Karbassi A. Removal of mercury from contaminated saline wasters using dithiocarbamate functionalized-magnetic nanocomposite. J. Environ. Manage. 2018;213:66-78.

40. Qi J, Yokoyama W, Masamba KG, Majeed H, Zhong F, Li Y. Structural and physico-chemical properties of insoluble rice bran fiber: Effect of acid-base induced modifications. RSC $A d v$. 2015;5:79915-79923.

41. Goswami M, Phukan P. Enhanced adsorption of cationic dyes using sulfonic acid modified activated carbon. J. Environ. Chem. Eng. 2017;5:3508-3517.

42. Patel M, Naik SN. Gamma-oryzanol from rice bran oil-A review. J. Sci. Ind. Res. (India). 2004;63:569-578.

43. Hong GB, Wang YK. Synthesis of low-cost adsorbent from rice bran for the removal of reactive dye based on the response surface methodology. Appl. Surf. Sci. 2017;423:800-809.

44. Antony GS, Manna A, Baskaran S, et al. Non-enzymatic reduction of $\mathrm{Cr}(\mathrm{VI})$ and it's effective biosorption using heat-inactivated biomass: A fermentation waste material. J. Hazard. Mater. 2020;392:122257.

45. Malek NNA, Jawad AH, Abdulhameed AS, Ismail K, Hameed BH. New magnetic Schiff's base-chitosan-glyoxal/fly ash/Fe3O4 biocomposite for the removal of anionic azo dye: An optimized process. Int. J. Biol. Macromol. 2020;31:530-539.

46. Ghabaee S, Behin J, Ansari M, Rajabi L. Synthesis and character- 
ization maleate-alumoxane nanoparticles for removal of reactive yellow 84 dye from aqueous solution. Adv. Powder Technol. 2020;146:1359-1368.

47. Ghanbarian M, Ghanbarian M, Mahvi AH, Tabatabaie T. Enhanced fluoride removal over $\mathrm{MgFe}_{2} \mathrm{O}_{4}$-chitosan-CaAl nanohybrid: Response surface optimization, kinetic and isotherm study. Int. J. Biol. Macromol. 2020;148:574-590.

48. Salehi H, Ebrahimi AA, Ehrampoush MH, et al. Integration of photo-oxidation based on UV/Persulfate and adsorption processes for arsenic removal from aqueous solutions. Ground. Sust. Dev. 2020;10:100338.
49. Dada AO, Olalekan AP, Olatunya AM, Dada O. Langmuir, Freundlich, Temkin and Dubinin-Radushkevich Isotherms Studies of Equilibrium Sorption of Zn 2+ Unto Phosphoric Acid Modified Rice Husk. IOSR J. Appl. Chem. 2012;3:38-45.

50. Guarin JR, Moreno-Pirajan JC, Giraldo L. Kinetic study of the bioadsorption of Methylene Blue on the surface of the biomass obtained from the Algae D. antarctica. J. Chem. 2018;5:2124845.

51. Das S, Mishra S. Insight into the isotherm modelling, kinetic and thermodynamic exploration of iron adsorption from aqueous media by activated carbon developed from Limonia acidissima shell. Mater. Chem. Phys. 2020;245:122751. 